Check for updates

Cite this: Food Funct., 2018, 9, 6187

\section{The antifungal activity of extracts of Osmundea pinnatifida, an edible seaweed, indicates its usage as a safe environmental fungicide or as a food additive preventing post-harvest fungal food contamination}

\author{
Paulo Silva, (D) a Chantal Fernandes, (DD ${ }^{b}{ }^{b}$ Lillian Barros, (D) ${ }^{c}$ Isabel C. F. R. Ferreira, (D) \\ Leonel Pereira (D) ${ }^{a}$ and Teresa Gonçalves (D) d,b
}

\begin{abstract}
In the present work, we explored the antifungal activity of the wild edible seaweed Osmundea pinnatifida (Rhodophyta) collected from the Portuguese coast, which is used as a food seasoning in Scotland, Ireland and Portugal. We performed a sequential extraction of the seaweed components with methanol, dichloromethane and $n$-hexane. These extracts showed an antifungal activity against Alternaria infectoria and Aspergillus fumigatus. The $n$-hexane fraction of the seaweed inhibited the sporulation of Alternaria infectoria at $30 \mu \mathrm{g} \mathrm{mL}^{-1}$ and induced a statistically significant $(P<0.001)$ decrease in $\beta$-glucan content. Furthermore, liquid cultures of Aspergillus fumigatus supplemented with $10 \mu \mathrm{g} \mathrm{mL}^{-1}$ of the $n$-hexane fraction showed abnormal conidiophores, completely devoid of phialides and conidia associated with a decrease of $18.3 \%$ in the chitin content $(P<0.01)$. The $n$-hexane fraction analysis by GC-MS revealed that it includes palmitic acid (29.6\%), phytol isomer 1 (12.8\%), oleic acid (9.6\%), stearic acid (6.2\%) and D-(-)-tagatofuranose (4.1\%), among other compounds present at lower concentrations. The present study reveals Osmundea pinnatifida as a promising source of biologically active compounds inhibiting fungal growth and conidiation, the main dispersal mechanism of filamentous fungi as Aspergillus fumigatus and Alternaria alternata, revealing its utility both as an environmental fungicide against fungal diseases and as a food preservative against fungal post-harvest food contamination.
\end{abstract}

Received 12th September 2018, Accepted 31st October 2018

DOI: $10.1039 / \mathrm{c} 8 \mathrm{fo} 01797 \mathrm{~b}$

rsc.li/food-function source for the pharmaceutical industry and for the emerging cosmetics industry and well-being. ${ }^{4}$

Seaweeds (or macroalgae) are photosynthetic marine organisms belonging to the Eukaryota domain and the kingdoms Plantae (the green and red algae) and Chromista (the brown algae, among others). Despite the fact that the phylogeny and taxonomy of the genus Osmundea have been controversial in the past, it is now strongly supported that this genus is a monophyletic group within the Laurencia complex. Osmundea pinnatifida belongs to the phylum Rhodophyta, class Florideophyceae, order Ceramiales, family Rhodomelaceae and tribe Laurenciae. ${ }^{5}$ o. pinnatifida is an edible macroalgae commonly known as pepper dulse, ${ }^{6}$ due to its slightly spicy flavour. This aromatic seaweed is dried and used as a pepperor curry-flavoured spice in Scotland, Ireland and Portugal, namely in the Azores islands. ${ }^{7}$ Fresh plants have a peculiar smell and flavour. ${ }^{7-9}$ O. pinnatifida is a good source of fiber, protein, dietary essential fatty acids, namely linoleic acid that cannot be synthesized by humans. ${ }^{10,11} \mathrm{O}$. pinnatifida is also a valuable source of vitamins $\mathrm{A}, \mathrm{E}$ and $\mathrm{K}$, polyunsaturated fatty 
acids, and minerals. ${ }^{12}$ The antioxidant properties, fatty acid profile, low omega-6/omega-3 and hypocholesterolemic/ hypercholesterolemic ratios observed, along with the nonanimal nature of the nutrients can have potential health benefits, turning it useful for the food supplement and/or the pharmaceutical industries. ${ }^{12}$

Filamentous fungi are both indoor and outdoor ubiquitous environmental organisms increasingly found as agents of infections both in plants and animals, and are recognized as one of the most prominent worldwide hazards to food security. ${ }^{13}$ Fungal impact in human health can be due to 3 groups of pathologies: (i) disseminated infections in immunocompromised patients, (ii) respiratory allergic diseases due to fungal sensitization and (iii) illness from ingestion of mycotoxins in contaminated foods and beverages. Aspergillus fumigatus is a saprotroph filamentous fungus considered as the filamentous fungi with the highest mortality among immunocompromised human patients and also one of the most important inducers of respiratory allergies. ${ }^{14}$ Aspergillus spp. are also phytopathogenic and asymptomatic endophytic organisms leading to the contamination of plants used in human nutrition. Its mycotoxins can be found, among others, in cereals, coffee, wine and peanuts. ${ }^{15}$ Aspergillus fumigatus stands out as the most prevalent airborne fungal pathogen in developing countries, causing severe and usually fatal invasive infections in immunocompromised hosts. This fungus sporulates abundantly, with every conidial head producing thousands of easily dispersed small $(2-3 \mu \mathrm{m})$ and slight conidia that are organized in phialides. These features turn them buoyant, keeping them airborne both indoors and outdoors. As a consequence, several thousands of conidia are daily inhaled by humans. ${ }^{16}$

Dematiaceous fungi are pigmented filamentous fungi which contain melanin in their cell walls and are ubiquitous saprophytes in water, soil, and vegetation and may be plant or animal pathogens. ${ }^{17,18}$ They can infect humans, causing a wide range of diseases, such as phaeohyphomycosis, chromoblastomycosis, and eumycotic mycetoma. ${ }^{18,19}$ Among the members of Dematiaceae, Alternaria species are increasingly found as aetiologic agents of human disease due to the growing number of immunocompromised patients. ${ }^{19,20}$ Alternaria spp. include important plant pathogenic species responsible for crop diseases that lead to worldwide economic losses such as the early blight of tomatoes and potatoes. ${ }^{21}$ They also produce mycotoxins that pose a serious risk to human and animal health because of their known toxicity and their frequent presence as natural contaminants in food. ${ }^{22}$

The inhalation of conidia from filamentous fungi such as Alternaria spp. or Aspergillus spp. has also been associated with IgE-mediated hypersensitivity reactions ranging from rhinitis and ocular symptoms to severe involvement of the lower respiratory tract including asthma with its life-threatening complications. $^{23-26}$

Fungicidal chemicals directed to plant diseases ${ }^{27}$ and to post-harvest food preservation are grouped according to their mode of action, with at least forty-five groups, including sterol biosynthesis inhibitors, strobilurins, and pyrazole carboxa- mides among others ${ }^{28}$ while the antifungal armamentarium for the treatment of animal and human fungal infections remains limited with only four different classes. For this purpose, enzymes involved in the biosynthesis of the fungal cell wall, lipid composition of the plasma membrane, including azoles, inhibitors of ergosterol synthesis, and DNA and protein synthesis have been targeted. ${ }^{29}$ However, one of the most serious health and environmental related threats is the emergence of resistance, cross-resistance between the different groups of antifungals, ${ }^{30}$ and environmental contamination with widespread fungicides such as azoles that lead to the parallel evolution of resistance to antifungals used in agriculture and in clinics. ${ }^{27,31}$ The fungal resistance issue together with the public health, societal and economic impact associated with the abusive use of fungicides lead to seeking for different and safer molecules targeting fungal pathogens, including the use of natural resources. One example of that is the new fungicide recently launched that is extracted from white lupin (Lupinus albus L.). ${ }^{32}$

In the present work, we evaluated the antifungal activity of O. pinnatifida extracts of methanol, dichloromethane and $n$-hexane on Alternaria infectoria and Aspergillus fumigatus using radial growth inhibition and standardized broth microdilution assays. The morphological alterations induced by these extracts were appraised by light, confocal and fluorescence microscopy. We also showed that $O$. pinnatifida extracts modulate Alternaria infectoria and Aspergillus fumigatus cell wall chitin and $\beta$-glucan. One of the most important outcomes of this work was the observation of the inhibitory effect of these extracts on the Alternaria infectoria and Aspergillus fumigatus conidiogenesis. It is suggested that this is due to the inhibition of MMD-Chs possibly by $\mathrm{D}-(-)$-tagatofuranose and pentakis(trimethylsilyl) ether (isomer 2) that have a furanose ring that shares structural homology with some known chitin synthase inhibitors and probably are able to bind to the active local of the MMD-Chs enzymes. Another hypothetical mechanism of action of this extract might be the inhibition of the synthesis of the MMD-Chs enzymes by the fatty acids present in the $O$. pinnatifida extract. The present study reveals Osmundea pinnatifida as a promising source of biologically active compounds that promote the inhibition of fungal conidiation. Since spores constitute the main dispersal mechanism of fungi, these active compounds show high potential as novel tools to be used as an antifungal agent. Moreover, since the filamentous fungi tested are responsible for spoilage of various food crops in the field, during post-harvest decay or during refrigerated transport and storage, as well as responsible for the production of toxic toxins contaminating food, the inhibition of fungal growth and conidiation would reduce food contamination and consequently, the presence of mycotoxins.

\section{Experimental}

\section{Organisms and media}

Aspergillus fumigatus CBS 500.90 and Alternaria infectoria CBS 137.90 were obtained from CBS-KNAW Fungal Biodiversity 
Centre (Utrecht, The Netherlands) and stored in sterile 20\% glycerol at $-80{ }^{\circ} \mathrm{C}$. Aspergillus fumigatus and Alternaria infectoria were cultured in potato dextrose agar (PDA; Difco) $\left(39 \mathrm{~g} \mathrm{~L} \mathrm{~L}^{-1}\right)$ at $30{ }^{\circ} \mathrm{C}$, with the latter strain being incubated under alternating $12 \mathrm{~h}$ light enriched with UV (lamp F15 W T8BLB; Grainger, USA) and $12 \mathrm{~h}$ dark periods.

\section{Seaweed collection and preparation of extracts}

O. pinnatifida specimens were collected in November 2013 at the rocky shore of Mondego Cape (40¹0' 557" N, 853' 819"), Figueira da Foz, Portugal. After being removed from the substrate, the algae were first washed with current seawater. At the lab, a new wash was carried out with seawater to remove epiphytes and incrusting material, and then the biomass was centrifuged with a manual spinner, weighed, washed with distilled water to remove salt, centrifuged, and hermetically stored at $-20{ }^{\circ} \mathrm{C}$.

Different $O$. pinnatifida extracts were prepared according to the method of Barreto et al. (2012) ${ }^{33}$ with slight modifications. Freeze-dried seaweed samples were ground to yield a powder, in which organic solvents of different polarities were added, namely methanol (>99\%), dichloromethane (>99\%) and $n$-hexane (99\%). The powder was placed in a beaker, methanol was added in a 4:1 ratio (solvent: sample powder; $\mathrm{mL} \mathrm{g}^{-1}$ ), and extraction was carried out for $12 \mathrm{~h}$ at room temperature, under continuous stirring and protected from light using aluminium foil. The content of the beaker was then filtered through Whatman ${ }^{\mathrm{TM}}$ filter paper, yielding the methanol extract (filtrate) and the sample powder (residue). The latter, after being dried at room temperature, was placed in a beaker with dichloromethane, added in a $4: 1$ proportion (solvent: sample powder, $\mathrm{mL} \mathrm{g}^{-1}$ ) and extracted under the above-described conditions. The content of the beaker was then filtered, yielding the dichloromethane extract. In turn, methanol extract was placed in a separatory funnel and $n$-hexane was added in a $1: 1$ proportion $(\mathrm{v} / \mathrm{v})$, proceeding to a liquid-liquid extraction. Thus, the methanol extract was partitioned, yielding the methanol and hexane fractions. The obtained extract and fractions were evaporated to dryness in a vacuum, using a rotary evaporator (Laborota 4000, Heidolph), at $40{ }^{\circ} \mathrm{C}$. Additionally, they were subjected to a nitrogen flow, pointing downward on the sample surface, to ensure that the solvent was completely evaporated. The dry biomass of dichloromethane and methanol fractions was solubilized in sterile ultrapure water and the dry biomass of the $n$-hexane extract was solubilized to a concentration of $6.4 \mathrm{~g} \mathrm{~L}^{-1}$ in ethanol $50 \%$ and then diluted in sterile ultrapure water. The final ethanol concentration present in these extracts was also tested as a control.

The extraction yield with methanol, dichloromethane and $n$-hexane was $4.19 \%, 0.33 \%$ and $0.35 \%$, respectively.

\section{Antifungal activity of $O$. pinnatifida extracts}

The O. pinnatifida organic extracts were screened for antifungal activity against Aspergillus fumigatus and Alternaria infectoria using a radial growth inhibition assay and a microdilution assay. For the radial growth inhibition assay, the extracts were added to PDA at $43{ }^{\circ} \mathrm{C}$ to obtain a final concentration of 10 and $100 \mu \mathrm{g} \mathrm{mL} \mathrm{mL}^{-1}$. Aspergillus fumigatus conidia suspensions were prepared in sterile $0.1 \%$ tween 80 at an OD of 2 at $600 \mathrm{~nm}$ placed in the centre of the Petri plate and incubated at $30{ }^{\circ} \mathrm{C}$ for 8 days. Alternaria infectoria conidia suspensions, prepared as described previously ${ }^{34}$ at a final concentration of $1 \times$ $10^{6}$ conidia per $\mathrm{mL}$, were applied on the surface of Petri dishes, and these plates were incubated for 8 days at $30{ }^{\circ} \mathrm{C}$ under a 12 h-alternating light and dark cycle. Fungal growth was assessed by measuring the colony diameter. The inhibitory growth effect of each extract against Aspergillus fumigatus and Alternaria infectoria was expressed as a percentage of inhibition of radial mycelial growth when compared with the control growth conditions (no extracts added to the medium).

The broth microdilution method, based on the CLSI M38-A standard (2002), was conducted as described previously. ${ }^{35}$ The multiwell plates were incubated at $30^{\circ} \mathrm{C}$, with orbital shaking at $120 \mathrm{rpm}$ for $48 \mathrm{~h}$ for Aspergillus fumigatus while for Alternaria infectoria this incubation was continued for $72 \mathrm{~h}$ under alternating $12 \mathrm{~h}$ light enriched with UV and $12 \mathrm{~h}$ dark cycles. Since the extracts did not prevent growth, it was not possible to determine the minimum inhibitory concentration (MIC). Instead, as described previously by us, ${ }^{35}$ the minimum effective concentration (MEC) was measured, which is defined as the lowest concentration of the drug yielding morphological alterations as described by others. ${ }^{36}$

The extracts were added to Yeast Malt Extract medium (YME medium: 4\% yeast extract, 10\% malt extract and 10\% glucose) at 10 and $100 \mu \mathrm{g} \mathrm{mL} \mathrm{m}^{-1}$, inoculated with $10^{4}$ conidia per $\mathrm{mL}$ and were incubated at $30{ }^{\circ} \mathrm{C}$ at $120 \mathrm{rpm}$ for $48 \mathrm{~h}$. Mycelia were observed by optical microscopy, using an Eclipse E400 epi-fluorescence microscope (Nikon, Japan) and images were recorded with a DS-5 M digital camera (Nikon, Japan).

\section{Determination of cell wall chitin content}

The mycelia used in this assay were obtained from Aspergillus fumigatus and Alternaria infectoria grown in YME liquid medium with or without extracts. Fungal inocula were prepared as described above, and the liquid cultures were incubated at $30{ }^{\circ} \mathrm{C}$, under constant orbital shaking at $120 \mathrm{rpm}$, for $72 \mathrm{~h}$; for Alternaria infectoria $12 \mathrm{~h}$-alternating light enriched with UV and a dark cycle, was used.

The cell wall chitin content quantification was based on the measurement of the glucosamine released by the acid hydrolysis of purified cell walls as described previously ${ }^{37}$ and the absorbance was read at $520 \mathrm{~nm}$ on a plate reader (SpectraMAX Gemini XM, Molecular Devices, USA).

\section{Determination of cell wall $\beta-(1,3)$-D-glucan content}

Quantification of $\beta$-(1,3)-D-glucan levels in the fungal cell walls was performed using the aniline blue assay as described previously. ${ }^{37}$ The fungal growth conditions, treatment and tissue harvesting were the same as those used for chitin quantification. Fluorescence was quantified by using a SpectraMAX Gemini EM, Molecular Devices, USA. 


\section{Fungal morphology study}

Fungal morphology was studied by fluorescence microscopy using calcofluor white (CFW) stain as described previously. ${ }^{37}$ Aspergillus fumigatus liquid cultures were prepared and grown in YME as described above for chitin and $\beta$-glucan quantifications. Alternaria infectoria was inoculated in $1.5 \mathrm{~mL}$ microtubes containing YME with $0.5 \%$ agar supplemented with the respective extracts and grown overnight at $150 \mathrm{rpm}$ under $12 \mathrm{~h}$ alternating UV light and dark cycles. ${ }^{37}$ Digital images were acquired with a Zeiss LSM 510 Meta confocal microscope and managed on a Zeiss LSM Image Browser (version 4.2.0.121; Carl Zeiss Inc.).

\section{Determination of the composition of the $n$-hexane fraction by gas chromatography-mass spectrometry (GC-MS)}

The derivatization was performed on the $n$-hexane fraction, which involved the derivatization of hydroxyl and carboxyl groups of the extracted compounds with $300 \mu \mathrm{L}$ of $\mathrm{N}, \mathrm{O}$-bis(trimethylsilyl)trifluoroacetamide (BSTFA; PanReac Applichem, Germany) by heating the resulting mixture at $70{ }^{\circ} \mathrm{C}$ for $1 \mathrm{~h}$ prior to analysis.

The derivatized sample was analyzed by GC-MS following a protocol previously described by Falcão et al. (2016), ${ }^{38}$ consisting of a PerkinElmer system with a Clarus ${ }^{\circledR} 580$ GC module and a Clarus ${ }^{\circledR}$ SQ 8 S MS module, equipped with a DB-5MS fusedsilica column $(30 \mathrm{~m} \times 0.25 \mathrm{~mm}$ i.d., film thickness $0.25 \mu \mathrm{m}$; J \& $\mathrm{W}$ Scientific, Inc.). The oven temperature was programmed, 45-175 ${ }^{\circ} \mathrm{C}$, at $3{ }^{\circ} \mathrm{C} \min ^{-1}$, subsequently at $15{ }^{\circ} \mathrm{C} \min ^{-1}$ up to $300^{\circ} \mathrm{C}$, and then held isothermal for $10 \mathrm{~min}$; injector and detector temperatures, $280{ }^{\circ} \mathrm{C}$. The transfer line temperature was $280{ }^{\circ} \mathrm{C}$; ion source temperature, $220{ }^{\circ} \mathrm{C}$; carrier gas, helium, adjusted to a linear velocity of $30 \mathrm{~cm} \mathrm{~s}^{-1}$; split ratio, 1:40; ionization energy, $70 \mathrm{eV}$; scan range, 40-300 $\mu$; scan time, $1 \mathrm{~s}$. The software Turbomass (software version 6.1.0, PerkinElmer, Shelton, CT, USA) for Windows was used for data acquisition. The identity of the components was assigned by comparison of their retention indices, relative to C7-C40 n-alkane indices and GC-MS spectra from a commercial MS database.

\section{Statistical analysis}

The experiments were performed in triplicate. Data were analyzed by Student's $t$ test using Prism (version 5) software (GraphPad Software, Inc., La Jolla, CA). Data are presented as the means \pm standard errors of the means (SEMs) and differences were considered significant at $P$ values of $<0.05$.

\section{Results and discussion}

\section{Antifungal activity of $O$. pinnatifida extracts against Alternaria infectoria and Aspergillus fumigatus}

The antifungal activity of the algae extracts was assessed using two different methodologies, radial growth inhibition assay and broth microdilution assay. The radial growth inhibition assay did not allow the observation of any reduction of the growth of Alternaria infectoria regardless of the concentration of the O. pinnatifida extracts tested $\left(10 \mu \mathrm{g} \mathrm{mL}^{-1}\right.$ or $\left.100 \mu \mathrm{g} \mathrm{mL}^{-1}\right)$ (results not shown). On the other hand, all the tested extracts were found to be effective against Aspergillus fumigatus, statistically significantly in relation to the control $(P<0.0001)$, and not significantly for $10 \mu \mathrm{g} \mathrm{mL} \mathrm{m}^{-1}$ of dichloromethane, reducing the radial growth, as compared with the control. The extracts tested at $10 \mu \mathrm{g} \mathrm{mL} \mathrm{m}^{-1}$ show a percentage of radial growth inhibition that ranges from $2.9 \%$ to $9.3 \%$, and from $7.8 \%$ to $14.6 \%$ for $100 \mu \mathrm{g} \mathrm{mL} \mathrm{m}^{-1}$ of extract (Table 1). Among the extracts in the study, the $n$-hexane fractions stand out as the most effective against Aspergillus fumigatus. Curiously, with $100 \mu \mathrm{g} \mathrm{mL} \mathrm{m}^{-1}$ of dichloromethane and $n$-hexane extracts the radial growth was not uniform, probably due to the low solubility of these extracts in the agar medium. For this reason, we appraised the inhibitory action of the extracts by the broth microdilution assay.

The microdilution assays did not reveal any apparent inhibitory effect of the seaweed extracts in any of the two tested fungal species at the tested concentrations. However, the observation of the mycelia under the microscope revealed changes in the production of conidia by Alternaria infectoria and by Aspergillus fumigatus when the mycelium was grown in the presence of the $n$-hexane fraction and dichloromethane extract. For this reason, we expressed the results in terms of MEC instead of MIC. For Alternaria infectoria, in the absence of $O$. pinnatifida extract (Fig. 1A) and in the presence of the methanolic seaweed fraction (Fig. 1B), the fungi presented a high number of conidia corresponding to the normal morphology of the fungus. We determined a MEC of $100 \mu \mathrm{g} \mathrm{mL}$ for the dichloromethane extract (Fig. 1C and D) and of 30 $\mu \mathrm{g} \mathrm{mL} \mathrm{m}^{-1}$ for the $n$-hexane fraction (Fig. $1 \mathrm{E}$ and $\mathrm{F}$ ) since at these concentrations and above, conidia were no longer observed.

Table 1 Effect of the different $O$. pinnatifida extracts, tested at $10 \mu \mathrm{g} \mathrm{mL}^{-1}$ and $100 \mu \mathrm{g} \mathrm{mL}^{-1}$, on colony diameter (CD; mm) and on radial growth inhibition (RGl; \%) of Aspergillus fumigatus

\begin{tabular}{|c|c|c|c|c|c|c|}
\hline \multirow[b]{2}{*}{ Extract } & \multicolumn{3}{|l|}{$10 \mu \mathrm{g} \mathrm{mL} \mathrm{L}^{-1}$} & \multicolumn{3}{|l|}{$100 \mu \mathrm{g} \mathrm{mL}^{-1}$} \\
\hline & $\mathrm{CD}(\mathrm{mm})($ mean $\pm \mathrm{SD})$ & RGI (\%) (\% of control $)^{a}$ & $P^{b}$ & $\mathrm{CD}(\mathrm{mm})($ mean $\pm \mathrm{SD})$ & RGI $(\%)(\% \text { of control })^{a}$ & $P^{b}$ \\
\hline Dichloro-methane & $74 \pm 2$ & 2.94 & ns & $70.2 \pm 0.3$ & 8.28 & $* * * *$ \\
\hline$n$-Hexane & $69 \pm 2$ & 9.28 & $* * * *$ & $65 \pm 9$ & 14.64 & $* * * *$ \\
\hline
\end{tabular}

${ }^{a}$ The control colony diameter was $76.50 \pm 0 \mathrm{~mm} .{ }^{b}$ Differences were analyzed by Student's $t$-test using Prism software and considered significant at $P$-values of $<0.05 .{ }^{* * *} P<0.0001$, ns: no significant difference. 

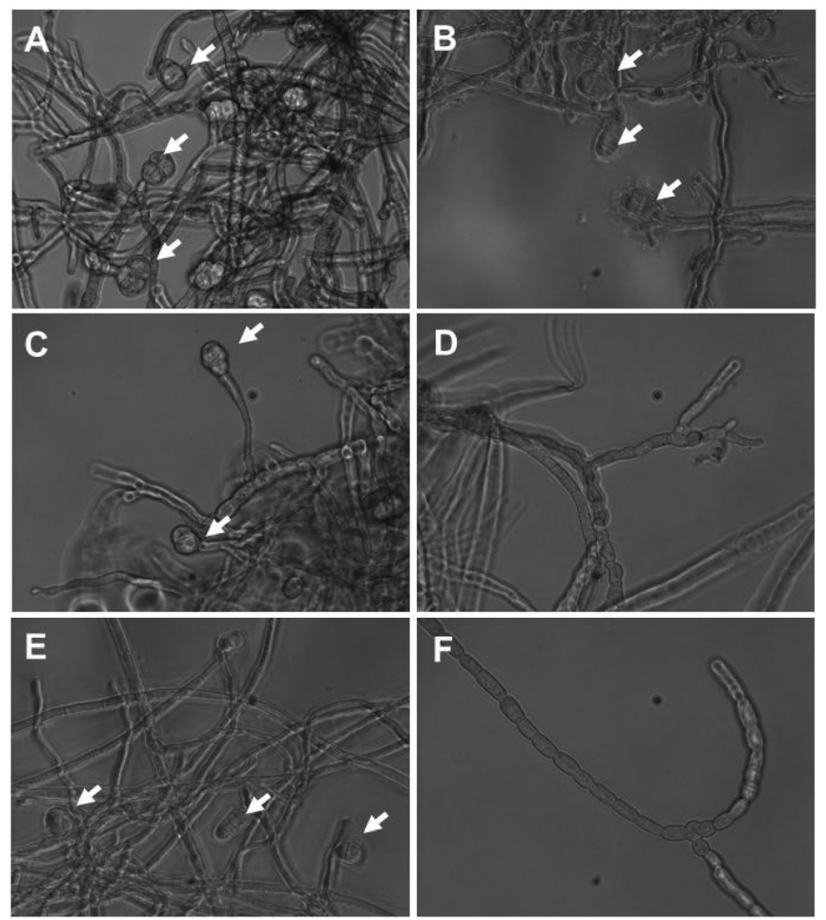

Fig. 1 Effect of $O$. pinnatifida extracts on the sporulation of Alternaria infectoria grown in RPMI 1640 medium for $72 \mathrm{~h}\left(30^{\circ} \mathrm{C}, 120 \mathrm{rpm}\right.$, under alternating $12 \mathrm{~h}$ light enriched with UV and $12 \mathrm{~h}$ dark cycles). An extractfree control (A) and treatments with $500 \mu \mathrm{g} \mathrm{mL}^{-1}$ of methanol (B), with $90 \mu \mathrm{g} \mathrm{mL}^{-1}$ (C) and $100 \mu \mathrm{g} \mathrm{mL}^{-1}$ of dichloromethane (D) and with $20 \mu \mathrm{g} \mathrm{mL}^{-1}(\mathrm{E})$ and $30 \mu \mathrm{g} \mathrm{mL}^{-1}$ of $n$-hexane (F) extracts are displayed. Images were captured with a DS-5M-L1 digital camera (Nikon, Japan), coupled to an Eclipse E400 epi-fluorescence microscope (Nikon, Japan) at $400 \times$ total magnification. Arrows indicate conidia.

In Aspergillus fumigatus, the MEC was also determined by microdilution and confirmed by liquid cultures in Erlenmeyer's flask with YME medium to verify whether the defects in conidiation induced by the extracts were not due to reduced aeration, under the conditions of the microdilution assays, i.e. run in multiwells (although the assay was run with orbital shaking). In liquid fungal cultures grown in Erlenmeyer's flask with orbital shaking, the aeration is improved thus suppressing any limitation due to appropriate gas changes. Whenever possible the CLSI M38-A standard methodology was followed with minor changes, including increased aeration that will improve the growth and will enable us to evaluate if the $O$. pinnatifida extracts delay or inhibit the growth of the conidia. The aerial mycelium ring above the medium surface was used for microscopic observation and confirmed the results obtained by microdilution.

In Aspergillus fumigatus, conidiation is a complex process that involves a multicellular reproductive structure called conidiophore. $^{39}$ The typical morphology of Aspergillus fumigatus conidial heads, shown under control conditions in Fig. 2A, is characterized by the presence of echinulate conidia produced in chains basipetally from phialides. These chains of conidia are borne directly on a broadly clavate vesicle located at the end of the conidiophore. ${ }^{39,40}$ The formation of conidiophores
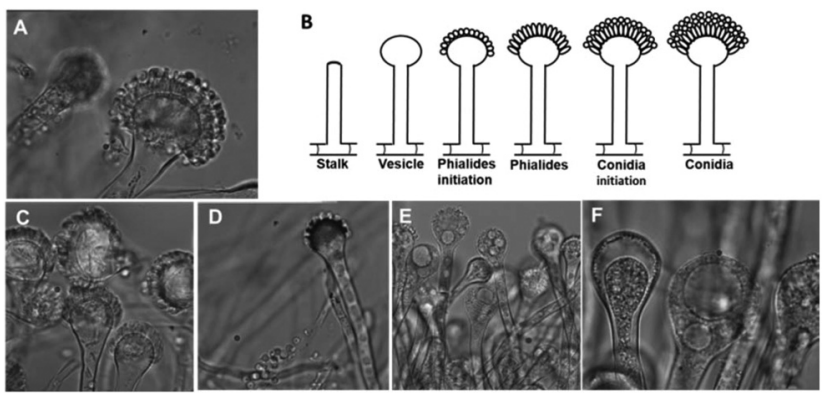

Fig. 2 Conidiophore morphology of Aspergillus fumigatus under control conditions and upon exposure to $O$. pinnatifida extracts. Images show Aspergillus fumigatus grown in YME (48 h; $\left.30{ }^{\circ} \mathrm{C} ; 120 \mathrm{rpm}\right)$ without (A; control) or with extract supplementation at $100 \mu \mathrm{g} \mathrm{mL}^{-1}$ for methanol (C) and dicholoromethane (D) and $10 \mu \mathrm{g} \mathrm{mL}^{-1}$ of $n$-hexane $(\mathrm{E}, \mathrm{F})$ extract. Images were captured with a DS-5M-L1 digital camera (Nikon, Japan), coupled to an Eclipse E400 epi-fluorescence microscope (Nikon, Japan) at 1000x total magnification (A and F), and 400x for $C, D$, and E. B represents a scheme of the normal development of Aspergillus fumigatus from an early conidiophore stalk, to a vesicle formation from the tip of the stalk, to a conidiophore with phialide initiation, to a conidiophore with phialides, to conidial initiation, and to a mature conidiophore bearing conidia.

begins with the growth of a conidiophore stalk that elongates by apical extension of an aerial branch in which the tip begins to swell in a structure called a conidiophore vesicle. From there on, phialides differentiate from the vesicles and form conidia chains. In Fig. 2B, we represent the normal development of Aspergillus fumigatus going through several stages: conidiophore stalk formation, evolution to a vesicle, then to a conidiophore with phialide initiation, mature phialide, conidia formation, and a finally mature conidiophore. As shown in Fig. 2C, only the methanol fraction did not provoke changes in the morphology of the conidial heads. The dichloromethane extract at $100 \mu \mathrm{g} \mathrm{mL}^{-1}$ leads to conidiophores with phialides that seem to be in an early stage of development (conidiophores with phialide initiation), not completely formed (Fig. 2D). Furthermore, the $n$-hexane fraction at concentrations $\geq 10 \mu \mathrm{g} \mathrm{mL}^{-1}$ led to an almost total extinction of phialides and conidia, as if the conidiation development was blocked in the vesicle phase leading to bold conidial heads. The resulting vesicles were highly vacuolized (Fig. 2E and F).

Loss of function mutations in any one of the genes involved in conidiogenesis blocks a specific stage, resulting in defective conidiophores that fail to produce mature conidia but the morphological defects that we observed in the present work have not been reported so far in these mutants. ${ }^{41-43}$

Table 2 summarizes the MEC values of $O$. pinnatifida extracts for Alternaria infectoria and Aspergillus fumigatus based on the morphological alterations observed about conidiation.

\section{Influence of $O$. pinnatifida extracts in fungal cell wall composition}

Cell wall chitin and $\beta$-glucan contents of mycelia of Alternaria infectoria and Aspergillus fumigatus were quantified after 
Table 2 Alternaria infectoria and Aspergillus fumigatus MEC of O. pinnatifida fractions $\left(\mu \mathrm{g} \mathrm{mL}^{-1}\right.$ )

\begin{tabular}{lll}
\hline & Dichloromethane & $n$-Hexane \\
\hline Alternaria infectoria & 100 & 30 \\
Aspergillus fumigatus & 100 & 10
\end{tabular}

exposure to $O$. pinnatifida extracts at the MEC concentrations. The results showed that while chitin levels remained almost unchanged, the $\beta$-glucan content of the Alternaria infectoria cell wall decreased in 3 days in the presence of $30 \mu \mathrm{g} \mathrm{mL}$ $n$-hexane (Fig. 3).

Treatment with $100 \mu \mathrm{g} \mathrm{mL}{ }^{-1}$ dichloromethane and $10 \mu \mathrm{g} \mathrm{mL}$ $n$-hexane led to a significant decrease in the cell wall chitin content of Aspergillus fumigatus (Fig. 4) without affecting the cell wall $\beta$-glucan contents. Since both the extracts decreased the cell wall chitin contents in Aspergillus fumigatus, we hypothesize that the observed effects in Aspergillus fumigatus conidiation upon exposure to these extracts might be associated with the verified reduction in chitin levels. Furthermore, the conidiation defects that we observed share a strong analogy with the phenotype observed in Aspergillus fumigatus mutants having defective MMD-Chs enzymes,

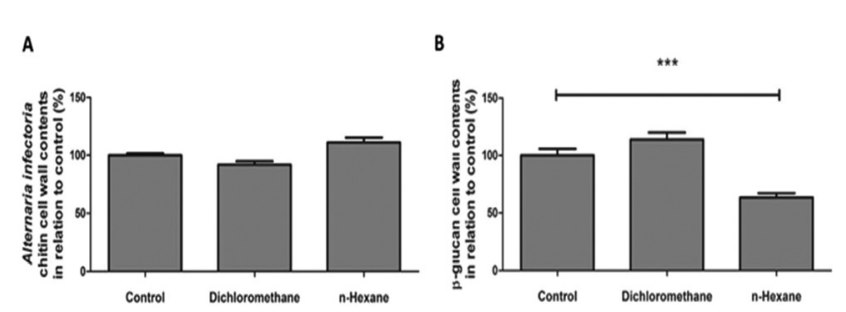

Fig. 3 Effects of $O$. pinnatifida extracts on the cell wall components of Alternaria infectoria. Chitin (A) and $\beta$-glucan (B) contents are presented. The strain was grown in liquid cultures $\left(72 \mathrm{~h} ; 30^{\circ} \mathrm{C}\right.$; under alternating $12 \mathrm{~h}$ light enriched with UV and $12 \mathrm{~h}$ dark cycles; $120 \mathrm{rpm}$ ) on YME without (control) or with extract supplementation $\left(100 \mu \mathrm{g} \mathrm{mL} \mathrm{m}^{-1} \mathrm{di}-\right.$ chloromethane and $30 \mu \mathrm{g} \mathrm{mL} \mathrm{m}^{-1} n$-hexane). Results are the average \pm SEM of three independent experiments ( $* * *, P<0.001, t$-test).
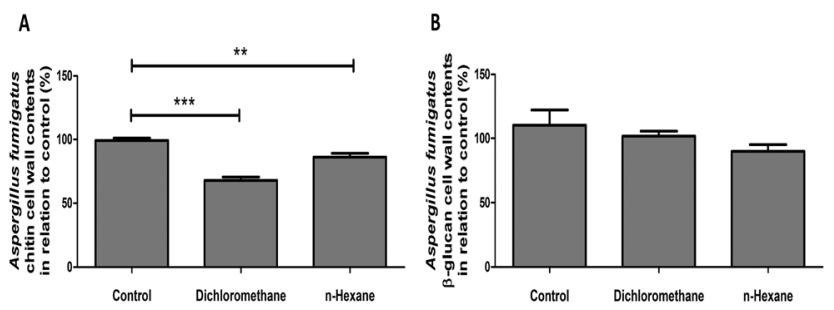

Fig. 4 Effects of $O$. pinnatifida extracts on the cell wall components of Aspergillus fumigatus. Chitin (A) and $\beta$-glucan (B) contents are displayed. The strain was grown in liquid cultures ( $48 \mathrm{~h} ; 30{ }^{\circ} \mathrm{C} ; 120 \mathrm{rpm}$ ) on YME without (control) or with extract supplementation $\left(100 \mu \mathrm{g} \mathrm{mL}^{-1} \mathrm{di}-\right.$ chloromethane and $10 \mu \mathrm{g} \mathrm{mL}^{-1} n$-hexane). Results are the average \pm SEM of three independent experiments $(* *, P<0.01 ; * * *, P<0.001$, $t$-test). namely the $\Delta \operatorname{csm} A, \Delta \operatorname{csm} B$ and $\Delta \operatorname{csm} A / \Delta \operatorname{csm} B$ mutants. ${ }^{44-46}$ Fungi contain various chitin synthases that have been reported to perform distinct functions at specific parts of the cell. ${ }^{47}$ Eight chitin synthase genes were identified in Alternaria infectoria $^{37}$ and Aspergillus fumigatus. ${ }^{45}$ Fungal Chs are distributed into seven classes. The class V and class VII Chs are characterized by the presence of a MMD domain and are crucial for conidiogenesis. ${ }^{48}$ Since the $n$-hexane fraction and to a lesser extent the dichloromethane extracts lead to disabled conidiogenesis, we hypothesize that the antifungal effect of the extracts tested is due to the inhibition of the MMD-Chs enzymes.

\section{Influence of $O$. pinnatifida extracts on chitin hyphal distribution}

The accumulation of chitin in the cell wall and septa of Alternaria infectoria and Aspergillus fumigatus was visualized using CFW fluorescence. As shown in Fig. 5A, confocal microscopy revealed that chitin is distributed uniformly along the hyphal trunk of Alternaria infectoria under control conditions and in the presence of MEC concentrations of dichloromethane and $n$-hexane fractions of $O$. pinnatifida seaweed and remains unchanged in the septa (Fig. 5B and C). Chitin was also accumulated uniformly along the hyphal trunks and conidial heads in Aspergillus fumigatus under the conditions tested (Fig. 5D and F, respectively), except for $100 \mu \mathrm{g} \mathrm{mL}{ }^{-1}$ dichloromethane (Fig. 5E). These results are in accordance with Fig. 4A that show a decrease in chitin levels when compared to the
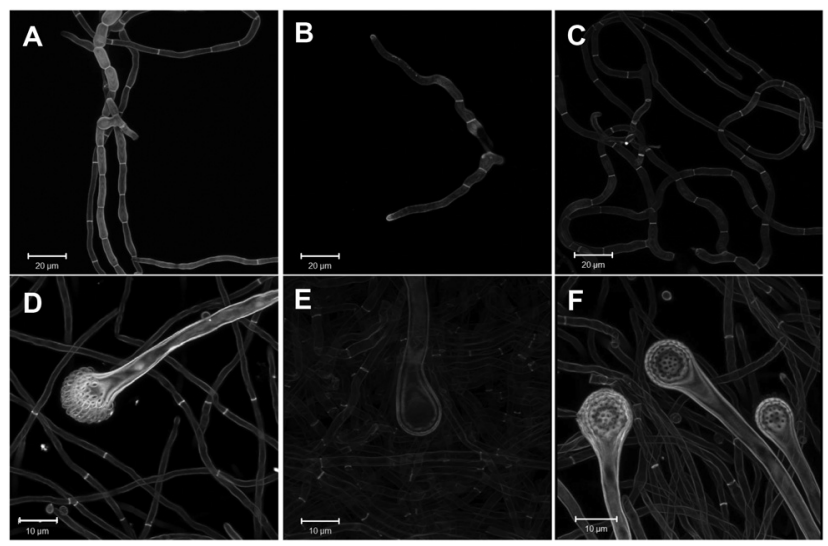

Fig. 5 Chitin distribution upon exposure of Alternaria infectoria (A, B, C) and Aspergillus fumigatus (C, D, E) to $O$. pinnatifida extracts. Images show a three-dimensional projection obtained by confocal imaging of chitin stained with CFW in Alternaria infectoria grown in YME with $0.5 \%$ agar (overnight; $30{ }^{\circ} \mathrm{C} ; 150 \mathrm{rpm}$; under alternating $12 \mathrm{~h}$ UV light and dark cycles) without $(A)$ or with extract supplementation (B, $100 \mu \mathrm{g} \mathrm{mL}^{-1} \mathrm{di}$ chloromethane and C, $30 \mu \mathrm{g} \mathrm{mL} \mathrm{m}^{-1} n$-hexane extracts) and Aspergillus fumigatus grown in YME (48 h; $30{ }^{\circ} \mathrm{C} ; 150 \mathrm{rpm}$; under alternating $12 \mathrm{~h}$ UV light and dark cycles) without (D) or with extract supplementation (E, $100 \mu \mathrm{g} \mathrm{mL}^{-1}$ dichloromethane and $\mathrm{F}, 10 \mu \mathrm{g} \mathrm{mL}^{-1} n$-hexane extracts). For each condition, maximum-intensity projections of $z$-stack images were obtained with FIJI software. Cell imaging was performed with a Zeiss LSM 510 Meta confocal microscope with a Plan-Apochromat 63x (numerical aperture 1.4) oil objective. 
other treatments, including the control. As already described the morphology of the conidiophores dramatically changed when Aspergillus fumigatus was grown in the presence of 10 $\mu \mathrm{g} \mathrm{mL}^{-1}$ of $n$-hexane extract. With this strategy of probing the distribution of chitin it could be observed that regardless of the absence of phialides and conidia, the normal pore-like structures are observed at the conidiophore surface, which could correspond to the anchor sites of phialides (Fig. 5F).

\section{Determination of the chemical composition of the wild type $n$-hexane extract}

Since the $n$-hexane $O$. pinnatifida fraction was the extract with a higher impact on Aspergillus fumigatus and Alternaria infectoria growth, we determined its chemical composition by gas chromatography-mass spectrometry (Table 3 ). This extract is mainly composed of palmitic acid (hexadecanoic acid, $29.60 \% \pm 0.60)$, phytol isomer $1(12.80 \% \pm 0.30)$, oleic acid (octadecenoic acid, 9.62\% \pm 0.14 ), stearic acid (octadecanoid acid, $6.15 \% \pm 0.02)$ and $\mathrm{D}-(-)$-tagatofuranose $(4.11 \% \pm 0.04)$ (Table 3).

The analysis of the chemical composition of the $n$-hexane extract leads to the prediction that the antifungal effect of this extract is due to the presence of $\mathrm{D}-(-)$-tagatofuranose, that harbours a carbohydrate ring with structural homology to the chitin synthase inhibitors nikkomycin Z, polyoxin A and polyoxin B. Nevertheless, we also showed that the $n$-hexane fraction contains palmitic acid (hexadecanoic acid) and low levels of phytol isomers, oleic acid (octadecenoic acid) and stearic acid

Table 3 Identification of volatiles of the $n$-hexane fraction of the algae O. pinnatifida (mean $\pm \mathrm{SD}$ )

\begin{tabular}{|c|c|c|}
\hline Components & $\mathrm{LR}_{\mathrm{E}}$ & $\begin{array}{l}\text { Area (relative } \\
\text { percentage \%) }\end{array}$ \\
\hline Benzoic acid & 1237.2 & $0.74 \pm 0.03$ \\
\hline Butane & 1270.2 & $0.24 \pm 0.01$ \\
\hline Glycerol & 1274.0 & $0.54 \pm 0.01$ \\
\hline Ketovaleric acid & 1313.2 & $0.48 \pm 0.01$ \\
\hline 3-Methylene-1,4-bis(trimethylsilyloxy) butane & 1326.0 & $0.28 \pm 0.01$ \\
\hline 3,8-Dioxa-2,9-disiladecane (isomer 1) & 1370.0 & $0.122 \pm 0.003$ \\
\hline 3,8-Dioxa-2,9-disiladecane (isomer 2) & 1385.2 & $0.099 \pm 0.001$ \\
\hline Heptadecane & 1695.8 & $3.74 \pm 0.01$ \\
\hline D- $(-)$-Tagatofuranose & 1813.1 & $4.11 \pm 0.04$ \\
\hline Phytol (isomer 1) & 1841.2 & $12.8 \pm 0.3$ \\
\hline Myristic acid (tetradecanoic acid) & 1856.2 & $7.8 \pm 0.4$ \\
\hline Phytol (isomer 2) & 1864.7 & $2.12 \pm 0.03$ \\
\hline Phytol (isomer 3 ) & 1880.5 & $4.1 \pm 0.2$ \\
\hline$n$-Pentadecanoid acid & 1944.1 & $0.91 \pm 0.02$ \\
\hline Palmitelaidic acid (trans-9-hexadecanoic acid) & 2018.3 & $3.4 \pm 0.1$ \\
\hline Palmitic acid (hexadecanoic acid) & 2050.0 & $29.6 \pm 0.6$ \\
\hline trans-9-Octadecenoic acid & 2211.7 & $7.0 \pm 0.3$ \\
\hline Oleic acid (cis-9-octadecenoic acid) & 2221.0 & $9.62 \pm 0.14$ \\
\hline Stearic acid (octadecanoid acid) & 2237.2 & $6.15 \pm 0.02$ \\
\hline cis-5,8,11,14,17-Eicosapentaenoic acid & 2364.9 & $2.4 \pm 0.1$ \\
\hline Heptacosene & 2689.9 & $0.54 \pm 0.02$ \\
\hline 9-Octadecenamide & 2777.5 & $0.617 \pm 0.004$ \\
\hline 3-Dodecyl-2,5-furandione & 2952.9 & $0.90 \pm 0.03$ \\
\hline Pregn-5-en-20-one & 3528.5 & $2.36 \pm 0.04$ \\
\hline
\end{tabular}

$\mathrm{RI}_{\mathrm{E}}$ - Experimentally obtained retention index relative to $\mathrm{C}_{8}-\mathrm{C}_{25}$ $n$-alkanes on the DB- 1 column. (octadecanoid acid) among other compounds, some of which were reported as having the antifungal properties, namely palmitic acid or oleic acid. ${ }^{49-51}$ However, the effects observed throughout this study, never described before, may be due to a single compound, or to a synergy between various compounds present in the extracts, even from those compounds found at lower concentrations. Although fatty acids may not be as effective as chemical fungicides, pathogenic fungi are less likely to become resistant to antifungal fatty acids. The most important target of antifungal fatty acids is the cell membrane, by increasing membrane fluidity, which result in leakage of the intracellular components and cell death. These compounds also target protein synthesis, fatty acid metabolism and topoisomerase activity. ${ }^{52}$

\section{Conclusions}

In the present work, in order to evaluate the antifungal properties of this edible seaweed, we fractionated the O. pinnatifida crude extract by a sequential extraction using three organic solvents namely, methanol, dichloromethane and $n$-hexane. With the first solvent, methanol, we obtained a seaweed extract with almost no antifungal potential. The second solvent, dichloromethane, led to a $O$. pinnatifida extract with a residual antifungal effect when used at higher concentrations than the extract resulting from the last solvent extraction, $n$-hexane, that exerts a potent antifungal action on Alternaria infectoria and Aspergillus fumigatus, namely inhibiting conidiogenesis. In fact, here we report that the $n$-hexane seaweed fraction strongly inhibits the sporulation rate of Alternaria infectoria and Aspergillus fumigatus, two filamentous fungi with distinct modes of conidial and conidiogenous cell development. Since the experimental assay begun with nongerminated spores, we conclude that the $n$-hexane fraction affected Alternaria infectoria and Aspergillus fumigatus sporulation, but not the germination process. This impairment is associated with a decrease in the $\beta$-glucan content of Alternaria infectoria and with a decrease of the chitin cell wall levels in Aspergillus fumigatus, indicating that in both fungi, the cell wall components are affected by the $n$-hexane fraction from O. pinnatifida.

Taken together, the results described here lead us to hypothesize that one or more bioactive compounds of O. pinnatifida impair the activity of MMD-Chs. The structure of the fructofuranose derivative $\mathrm{D}-(-)$-tagatofuranose indicates that this is a strong candidate for inhibiting specifically these enzymes.

Since the infectious life cycle of filamentous fungi usually begins with the production of conidia that are small enough to reach alveoli after inhalation, ${ }^{53}$ several efforts have been made to understand the underlying mechanisms of sporulation in fungus, and the finding of compounds inhibiting conidiogenesis is welcome. We may also speculate that the $O$. pinnatifida crude extracts can be used in agriculture as a fertilizer, like other seaweeds currently used, ${ }^{54}$ with the advantage of protect- 
ing crops from fungal spoilage, reducing also the presence of mycotoxins in food. This crude extract could also be used for inhibition or prevention of fungal contamination during postharvest decay, refrigerated transport or storage of crops.

\section{Conflicts of interest}

There are no conflicts of interest to declare.

\section{Acknowledgements}

The authors are grateful to the Foundation for Science and Technology (FCT, Portugal) and the FEDER under Programme PT2020 for financial support to CIMO (UID/ AGR/00690/2013) and L. Barros contract. This study was partly supported by FEDER funds through the Operational Programme Competitiveness Factors-COMPETE and national funds by FCT-Foundation for science and Technology under the strategic project UID/NEU/04539/ 2013. C. Fernandes is a recipient of a postdoctoral fellowship from FCT-Fundação para a Ciência e Tecnologia (SFRH/ BPD/63733/2009). The authors also acknowledge financial support from the Portuguese Foundation for Science and Technology, through the strategic project UID/MAR/04292/ 2013 granted to MARE.

\section{References}

1 B. K. Carté, Bioscience, 1996, 46, 271-286.

2 L. Pereira, Therapeutic and Nutritional Uses of Algae, Science Publishers' (SP), An Imprint of CRC Press/Taylor \& Francis Group, 2018, p. 560. ISBN 9781498755382.

3 M. J. Garson, in Marine Chemical Ecology, ed. J. B. McClintock and B. J. Baker, CRC Press, 1st edn, 2001, pp. 71-114.

4 L. Pereira and F. Correia, Macroalgas Marinhas da Costa Portuguesa - Biodiversidade, Ecologia e Utilizações, Nota de Rodapé Ed., 1st edn, 2015.

5 M. Guiry and G. Guiry, Osmundea pinnatifida (Hudson) Stackhouse. AlgaeBase, World-wide Electronic Publication. Retrieved 2018, from http:/www.algaebase.org/search/ species/detail/?species_id=E77119a59a2610f82\&-session= abv4:05F953B611c6f2C0C9uG1BBC9C95.

6 L. Pereira, Edible Seaweeds of the World, Science Publishers. Science Publishers' (SP), An Imprint of CRC Press/Taylor \& Francis Group, 2016, p 448. ISBN 9781498730471.

7 L. Pereira, Osmundea pinnatifida (Hudson) Stackhouse. MACOI, Portuguese Seaweeds Website. World-wide Electronic Publication, 2018, Retrieved July 23, 2018, from http://macoi.ci.uc.pt/spec_list_detail.php?spec_id=122.

8 L. Pereira, Guia ilustrado das macroalgas: conhecer e reconhecer algumas espécies da flora portuguesa, Imprensa da Universidade de Coimbra, 2009.
9 M. Machín-Sánchez, J. Díaz-Larrea, M. T. Fujii, A. Sentíes, V. Cassano and M. C. Gil-Rodríguez, Afr. J. Mar. Sci., 2012, 34, 27-42.

10 R. F. Patarra, L. Paiva, A. I. Neto, E. Lima and J. Baptista, J. Appl. Phycol., 2011, 23, 205-208.

11 R. F. Patarra, J. Leite, R. Pereira, J. Baptista and A. I. Neto, Nat. Prod. Res., 2013, 27, 665-669.

12 L. Paiva, E. Lima, R. F. Patarra, A. I. Neto and J. Baptista, Food Chem., 2014, 164, 128-135.

13 E. Pennisi, Science, 2010, 327, 804-805.

14 F. Bongomin, S. Gago, R. O. Oladele and D. W. Denning, J. Fungi, 2017, 3, 57.

15 E. R. Palencia, D. M. Hinton and C. W. Bacon, Toxins, 2010, 2, 399-416.

16 T. R. Dagenais and N. P. Keller, Clin. Microbiol. Rev., 2009, 22, 447-465.

17 G. S. de Hoog, J. Guarro, J. Gené and M. J. Figueras, Atlas of Clinical Fungi, Centraalbureau voor Schimmelcultures, Utrecht, The Netherlands, and Universitat Rovira i Virgili, Reus, Spain, 2nd edn, 2000, p. 1126.

18 S. G. Revankar and D. A. Sutton, Clin. Microbiol. Rev., 2010, 23, 884-928.

19 M. Gilaberte, R. Bartralot, J. M. Torres, F. S. Reus, V. Rodríguez, A. Alomar and R. M. Pujol, J. Am. Acad. Dermatol., 2005, 52, 653-659.

20 A. Gaur and P. M. Flynn, Semin. Pediatr. Infect. Dis., 2001, 12, 279-287.

21 V. Singh, A. Shrivastava, S. Jadon, N. Wahi, A. Singh and N. Sharma, Int. J. Agric. Sci., 2015, 7, 834-840.

22 H. B. Lee, A. Patriarca and N. Magan, Mycobiology, 2015, 43, 93-106.

23 R. Rid, K. Onder, S. MacDonald, R. Lang, T. Hawranek, C. Ebner, W. Hemmer, K. Richter, B. Simon-Nobbe and M. Breitenbach, Mol. Immunol., 2009, 46, 3476-3487.

24 R. K. Bush and J. J. Prochnau, J. Allergy Clin. Immunol., 2004, 113, 227-234.

25 A. P. Knutsen, R. K. Bush, J. G. Demain, D. W. Denning, A. Dixit, A. Fairs, P. A. Greenberger, B. Kariuki, H. Kita, V. P. Kurup, R. B. Moss, R. M. Niven, C. H. Pashley, R. G. Slavin, H. M. Vijay and A. J. Wardlaw, J. Allergy Clin. Immunol., 2012, 129, 280-291.

26 D. W. Denning, C. Pashley, D. Hartl, A. Wardlaw, C. Godet, S. Del Giacco, L. Delhaes and S. Sergejeva, Clin. Transl. Allergy, 2014, 4, 14.

27 M. C. Fisher, N. J. Hawkins, D. Sanglard and S. J. Gurr, Science, 2018, 360, 739-742.

28 D. W. Hollomon, Plant Prot. Sci., 2015, 51, 170-176.

29 A. T. Sangamwar, U. D. Deshpande and S. S. Pekamwar, Indian J. Pharm. Sci., 2008, 70, 423-430.

30 M. C. Arendrup and D. S. Perlin, Curr. Opin. Infect. Dis., 2014, 27, 484-492.

31 M. M. Azevedo, I. Faria-Ramos, L. C. Cruz, C. Pina-Vaz and A. G. Rodrigues, J. Agric. Food Chem., 2015, 63, 74637468.

32 S. Monteiro, A. Carreira, R. Freitas, A. M. Pinheiro and R. B. Ferreira, PLoS One, 2015, 10, e0122095. 
33 M. C. Barreto, E. Mendonça, V. Gouveia, C. Anjos, J. S. Medeiros and A. M. L. Seca, Life Mar. Sci., 2012, 29, 53-58.

34 C. Fernandes, R. Prados-Rosales, B. Silva, A. NakouziNaranjo, M. Zuzarte, S. Chatterjee, R. E. Stark, A. Casadevall and T. Gonçalves, Antimicrob. Agents Chemother., 2016, 60, 1646-1655.

35 F. Soares, C. Fernandes, P. Silva, L. Pereira and T. Gonçalves, J. Appl. Phycol., 2016, 28, 2991-2998.

36 M. B. Kurtz, I. B. Heath, J. Marrinan, S. Dreikorn, J. Onishi and C. Douglas, Antimicrob. Agents Chemother., 1994, 38, 1480-1489.

37 C. Fernandes, J. Anjos, L. A. Walker, B. M. A. Silva, L. Cortes, M. Mota, C. A. Munro, N. A. Gow and T. Gonçalves, Antimicrob. Agents Chemother., 2014, 58, 2894-2904.

38 S. I. Falcão, C. Freire, A. C. Figueiredo and M. V. Boas, Rec. Nat. Prod., 2016, 10, 176-188.

39 J. P. Latgé, Clin. Microbiol. Rev., 1999, 12, 310-350.

40 C. R. Mahon, D. C. Lehman and G. Manuselis Jr., Textbook of diagnostic microbiology, ed. E. Wurm-Cutter, Elsevier Health Sciences, 5th edn, 2014.

41 L. Tao and J. H. Yu, Microbiology, 2011, 157, 313-326.

42 J.-H. Mah and J.-H. Yu, Eukaryotic Cell, 2006, 5, 1585-1595.

43 J.-H. Yu, J.-H. Mah and J.-A. Seo, Eukaryotic Cell, 2006, 5, 1577-1584.
44 E. Mellado, A. Aufauvre-Brown, N. A. R. Gow and D. W. Holden, Mol. Microbiol., 1996, 20, 667-679.

45 C. Jiménez-Ortigosa, V. Aimanianda, L. Muszkieta, I. Mouyna, D. Alsteens, S. Pire, R. Beau, S. Krappmann, A. Beauvais, Y. F. Dufrêne, C. Roncero and J.-P. Latgé, Antimicrob. Agents Chemother., 2012, 56, 61216131.

46 A. Aufauvre-Brown, E. Mellado, N. A. R. Gow and D. W. Holden, Fungal Genet. Biol., 1997, 21, 141-152.

47 C. A. Munro and N. A. R. Gow, Med. Mycol., 2001, 39, 4153.

48 C. Fernandes, N. A. R. Gow and T. Gonçalves, Fungal Biol. Rev., 2016, 30, 1-14.

49 C. Altieri, D. Cardillo, A. Bevilacqua and M. Singaglia, J. Food Prot., 2007, 70, 1206-1212.

50 S. Liu, R. Weibin, L. Jing, X. Hua, W. Jingan, G. Yubao and W. Jingguo, Mycopathologia, 2008, 166, 93-102.

51 D. Walters, L. Raynor, A. Mitchell, R. Walker and K. Walker, Mycopathologia, 2004, 157, 87-90.

52 C. H. Pohl, J. L. F. Kock and V. Thibane, Antifungal free fatty acids: A Review, in Science against microbial pathogens: communicating current research and technological advances, ed. A. Méndez-Vilas, 2011, vol. 1.

53 J. A. Wasylnka and M. M. Moore, J. Cell Sci., 2003, 116, 1579-1587.

54 J. S. Craigie, J. Appl. Phycol., 2011, 23, 371-393. 